\title{
Pediatri Uzmanı ve Asistanlarının Astım Tedavisinde Kullanılan İlaçlar Hakkındaki Bilgi Düzeylerinin Değerlendirilmesi
}

\author{
To Evaluate the Level of Knowledge of the Pediatricians About the Drugs Used in the Treatment of Asthma \\ Fatih ÇİÇEK ${ }^{1}$, Mahmut DOĞRU ${ }^{2}$, Rabia Gönül SEZER ${ }^{2}$, Burçin Çi̇ÇEK ${ }^{3}$ \\ Tarı KIRKGÖZ ${ }^{4}$, Abdulkadir BOZAYKUT ${ }^{2}$ \\ 1. Bursa Uludağ Üniversitesi, Çocuk İmmünolojisi ve Alerjisi Bilim Dalı, Bursa, Türkiye \\ 2. Sağlık Bilimleri Üniversitesi, Zeynep Kamil Kadın ve Çocuk Hastalıkları Eğitim ve Araştırma Hastanesi, İstanbul, Türkiye \\ 3. Bursa Çekirge Devlet Hastanesi, Zübeyde Hanım Doğumevi, Bursa, Türkiye \\ 4. Marmara Üniversitesi, Pendik Eğitim ve Araştırma Hastanesi, Çocuk Endokrin Bilim Dalı, İstanbul, Türkiye
}

\section{$\ddot{O Z Z T}$}

Amaç: Astım, öksürük, hışıltı, nefes darlı̆̆g ve göğüste sıkıșma hissi gibi tekrarlayıcı solunum semptomları ile seyreden çocukluk çağının en sık rastlanan akut ve kronik enflamatuar solunum yolu hastalığıdır.Genel pediatri uzmanlığında çocukluk çă̆ı astımı ve tedavisi konusunda yeterli bilgi düzeyi etkin kontrol için gereklidir. Bu çalışmada, pediatristlerin çocukluk çağı astımında kullanılan ilaçlar konusunda bilgi ve uygulamalarının değerlendirilmesi amaçlanmıştır.

Gereçler ve Yöntem: Çalışmamıza 200 çocuk sağlığı ve hastalıkları uzmanı veya asistan hekimi katıldı. Astım tedavisinde kullanılan ilaçlar ilgili toplam 40 soruluk anket hekimlere uyguland1.

Bulgular: Uzman hekimlerin ve hekimlik süresi 5 yıldan fazla olanların anket sorularına verdikleri doğru cevap sayıları, asistan hekimlerin ve hekimlik süresi 5 yildan daha az olanların verdikleri doğru cevap sayısından anlamlı olarak daha yüksekti (p: 0.001). Cinsiyetin teste doğru cevap verme açısından anlamlı bir farklılık oluşturmadığı görüldü (p: 0,881).

Sonuç: Astım kılavuzları ve pratik yaklaşımda bir kısım farkl1lıklar olsa da çocuk hekimlerinin çoğu yaklaşımları kılavuzlara uygunluk göstermektedir. Hekimlik süresi ve uzman veya asistan olmak anlamlı olarak fark yaratmışken, cinsiyetin anlam11 farklılık yaratmadığı görülmüştür. Ancak astımlı çocuklara daha etkin ve standartize tedavi verilebilmesi için mezuniyet sonrası düzenli aralıklarla eğitimin gerekli olduğu düşünülmektedir.

Anahtar Kelimeler: astım, astım atağı, astım tedavisi, pediatrist, bilgi düzeyi

\section{ABSTRACT}

Objective: Asthma is the most common acute and chronic inflammatory airway disease of childhood with recurrent respiratory symptoms such as shortness of breath, wheezing, chest tightness and cough. Adequate knowledge about childhood asthma and treatment in general pediatric expertise is essential for effective control of the disease. The aim of this study was to evaluate the knowledge and practices of pediatricians on drugs used in childhood asthma.

Material and Methods: 200 children health and disease specialists or assistant physicians participated in our study. A total of 40 questions about the drugs used in the treatment of asthma were applied to physicians.

\section{İletișim}

Sorumlu Yazar: Uzm.Dr. Fatih ÇİÇEK

Adres: Uludağ Üniversitesi, Çocuk İmmünolojisi ve Alerjisi Bilim Dalı, 16059 Görükle, Bursa, Türkiye

Tel: +90 (507) 6118401

E-Posta: drfatihcck@gmail.com

Makale Geliş: 05.02.2019

Makale Kabul: 06.02.2020

DOI: http://dx.doi.org/10.16948/zktipb.522255
Results: The number of correct answers given to the test by the specialists and the physicians more than 5 years was significantly higher than the number of correct answers given by the asistant physicians and the physicians with less than 5 years (p: 0.001). Gender showed no significant difference in terms of responding to the test (p: 0,881).

Conclusion: Although there are some differences in asthma guidelines and practical approach, most of the pediatricians comply with the guidelines. The duration of the job and being an expert or assistant make a significant difference, gender showed no significant difference in terms of responding to the test. It is believed that education is necessary at regular intervals after graduation in order to provide more effective and standardized treatment for children with asthma.

Keywords: asthma, asthma attack, asthma treatment, pediatricians, knowledge survey

\section{GÍRIŞ}

Astım; nefes darlığı, hış1ltı, göğüste sıkışma hissi ve öksürük gibi tekrarlayıcı solunum semptomları ile seyreden, genellikle kendiliğinden gerileyen geri dönüşümlü hava yolu obstrüksiyonu ve artmış bronşiyal duyarlılığın eşlik ettiği çocukluk çağının en sik rastlanan akut ve kronik enflamatuar solunum yolu hastalığıdır. Astımı olan kişilerde belirtiler ve hastalığın şiddeti değişkenlik göstermekte olup bu, hastalığın heterojen özelliğini yansıtmaktadır (1). Astım sıklığı ülkeden ülkeye, ülkenin bir bölgesinden diğerine, 1rka, çevresel faktörlere göre değişiklik göstermektedir. Çevre ve hava kirliliği, sigara, değișen yaşam koşulları, diyet alışkanlıklarında değişiklikler ve tam olarak açıklanamamış genetik faktörler bu farkl111ktan sorumlu tutulmaktadır. Ülkemizde 6-12 yaş arası çocuklarda astım prevalansının, 1995'de \%9,8 iken, 2004' de \%17,8'e yükseldiği saptanmıştır. Dünyada da astım tedavi ve kontrolündeki gelişmelere rağmen, çocukluk çağ 1 astım prevelansında her 10 yılda bir $\% 50$ oranında artış bildirilmektedir (2). Acil servislere başvuran çocukların \%6-8'inden akut astım ataklar1 sorumlu olup, bu hastaların \%15-20'sinin acil serviste gözlem altında tutulması veya yatırılması gerekmektedir (3).

Astım hastalığının başarılı bir şekilde tedavi edilebilmesi için tanının doğruluğundan emin olunmalıdır. Astım tanısının klinik bir tanı olduğu unutulmamalıdır. Bu, tanı özgeçmiş ve soygeçmiş öyküleriyle desteklenmeli, yardımcı laboratuvar yöntemleriyle pekiştirilmeli ve olası bazı benzer 
hastalıklar ekarte edilmelidir (3). Çocukluk çağı astımında tedavinin amacı; semptomların kontrolü ve kontrolün devamının sağlanması, atakların önlenmesi, yaşam kalitesinin bozulmasının önlenmesidir. Hekimler, tedavinin hastalara etkin bir şekilde uygulanması konusunda eğitici olmalılardır. Tedavi yöntemi seçilirken etkinliği, maliyeti, güvenliği, kullanım kolaylığı, uygunluğu ve hastanın yaşı dikkate alınmalıdır (4-5).

Ülkemizde yapılan çalışmalar sonucunda, hastaların doktorlar tarafindan tanı almakta sikıntı yaşadığ1 gözlenmektedir(6). Astımla ilgili pek çok ulusal ve uluslararası kılavuz olmasına rağmen tanı ve tedavi de halen eksiklikler olmaktadır $(7,8)$.

Astım çocukluk çağının sık karşılaşılan pediatrik sağlık sorunlarından biri olduğu için, genel pediatri uzmanlarından çocukluk çağı astım tedavisinin düzenlenmesi konusunda yeterli bilgi ve beceri düzeylerine sahip olmaları beklenmektedir. Bu çalıșmada, çocuk hekimlerinin çocukluk çağı astımının tedavisinde kullanılan ilaçların klinik ve yan etkileri konusunda bilgi düzeylerinin değerlendirilmesi amaçlanmıştır.

\section{GEREÇ ve YÖNTEM}

Çalıșmamız 01.08.2014 ile 01.06.2015 tarihleri arasında yapılmış kesitsel bir çalışmadır. Araştırmamız ile ilgili son Türk Toraks Derneği Astım Tanı ve Tedavi Rehberi esas alınarak derlenen 40 soruluk anket formu (Tablo 1), toplam 200 çocuk sağlığı ve hastalıkları uzman ve asistan hekimlerine dağıtılmıştır. Katılım, gönüllülük esası göz önüne alınarak olmuş, ankete katılmak isteyenlere anket formu verilmiștir. Bilgilendirilmiş olur alındıktan sonra, yüz yüze görüşme yöntemiyle anket soruları doldurulmuştur.

Anket formu 3 bölüm halinde hazırlanmıs toplam 40 sorudan oluşturulmuştur. 1. bölümde demografik özellikler (yaş, cinsiyet, görev süresi, çalıştığı kurum, astım hastası görme sıklığı), 2. bölümde astım tedavisinde kullanılan ilaçlarla ilgili bilgi durumunu değerlendirmeye yönelik 25 soru, 3. bölümde astım tedavisi konusundaki yaklaşım ve bilgilerini değerlendirmeye yönelik ifadelerden oluşan toplam 15 soru şeklinde hazırlanmıştır. İkinci ve üçüncü bölümdeki sorulara doğru cevap verenlere " 2,5 " puan, yanlış cevap verenlere " 0 " puan verilmiştir. Sorular karışık olarak yerleștirilmiş, katılımc1lara herhangi bir süre kısıtlaması yapılmamıș ve yardımda bulunulmamıștır. Anket formu ve sorular yanıtlandığında, yanıtlanmamış anket sorusu veya bilgi düzeyi sorusu olup olmadığ kontrol edilmiş, kişilerin boş kalan yerleri de doldurması ve birden fazla yanıtları varsa kendilerine en doğru gelen yanıtı seçmeleri istenmiștir. Çalıșmamızda bilgi düzeyi teorik olarak değerlendirilmiştir. Bir anket çalışması olduğu için katılımcılar klinik deneyimlerine ve hafiza faktörüne bağlı olarak cevaplar vermişlerdir. Ankete katılanlara objektif olarak ölçme ve değerlendirme uygulamaları da yapılmamıştır.

Çalışma için yerel etik kurul onayı alındı. (Zeynep Kâmil Kadın ve Çocuk Hastalıkları Eğitim ve Araştırma Hastanesi Klinik Araştırmalar Etik Kurulu 06.06.2014 tarihli, 97 onay numaral1).

\section{İSTATİKSEL DEĞERLENDİRME}

Anket formları hazırlanan veri kodlama k1lavuzu doğrultusunda kodlanarak bilgisayarda SPSS (Statistical Package for Social Sciences for Windows) 16 istatistik programına kaydedilmiş, yine bu program kullanılarak analizler yapılmıştır. Çalışmanın bulguları frekans ve yüzde şeklinde belirtilmiştir. İstatistiksel hesaplamalarda Mann Whitney U Testi ve Kruskal Wallis Varyans analizi testleri, istatistiksel karşılaştırmada Ki- Kare (Chi- Square Test) testi kullanılmış, önemlilik için $p<0,05$ olarak kabul edilmiştir.

\section{BULGULAR}

Çalışmaya katılan 200 çocuk hekiminin \%68'i kadın (n: 136) ve \%32'si erkek (n: 64) olup ortala-

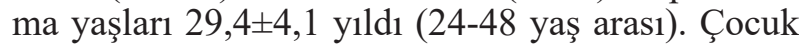
hekimlerinin ortalama çalışma süresi $4,8 \pm 3,8$ y1l bulundu (1-24 yıl aras1). Hekimlerin \%81'i (n:162) asistan, \%19'u (n:38) çocuk sağlığı ve hastalıkları uzmanıydı. Bunların \%60'ının (n:120) Sağlık Bakanlığ 1 Eğitim ve Araştırma Hastanesinde, \%40'ının (n:80) üniversite hastanesinde çalıştığ tespit edildi. 5 yıldan uzun süre hekimlik yapma oran1 \%33 idi. Hekimlerin klinikte astım hastası görme sıklığı ortalama yüzde $15,6 \pm 14,4$ /hafta olarak bulundu.

Astım tedavisinde kullanılan ilaçlarla ilgili bilgi durumunu ölçmeye ve değerlendirmeye yönelik sorulara verilen yanıtlara bakıldığında; 5 yıldan uzun süre hekimlik yapanların sorulara daha fazla oranda doğru yanıt verdikleri görülmüştür. Hekimlerin toplam 25 soruya 100 puan üzerinden ortalama $54,6 \pm 14,1$ ald 1 , en az 5 , en fazla 23 soruya doğru cevap verdikleri hesaplandi. 'Siklesonid düşük dozu ne kadardır?" ve "Siklesonid yüksek dozu ne kadardır?" cümleleri çocuk hekimlerinin en çok hata yaptığ1 sorulard1. Sirasıyla \%73,5 ve \%71 oranlarında yanlış cevap verildi. En fazla tam doğru cevap "Salbutamol etki başlangıç zamanı" sorusu ve "Günlük olarak 100-200 mcg inhaler kortikosteroid ile büyüme üzerine olumsuz etki bildirilmemiștir." cümlelerine verildi. Doğruluk oranları sirasıyla $\% 85,5$ ve $\% 80,5$ ' idi.

Astım tedavisi konusundaki yaklaşım ve bilgi düzeylerini değerlendirmeye yönelik sorulara verilen yanıtlara bakıldığında; cinsiyet ( $\mathrm{p}: 0,84)$, çalıştığ 1 kurum ( $p: 007)$, hekimlik süresi $(p=0,12)$ anlamlı olarak farkl11ı yaratmazken, uzman doktor olmanın $(\mathrm{p}=0,001)$ anlamlı olarak fark yaratt1$\breve{\text { g}} 1$ görülmüştür. Hekimlerin toplam 15 soruya 100 puan üzerinden ortalama $60,7 \pm 12,3$ puan aldığ 1 , en az 4, en fazla 14 soruya doğru cevap verdikleri hesapland1. "Sürekli tedavi gereksinimi olan hastalarda ilk seçenek orta doz inhaler kortikosteroidlerdir. Alternatif olarak lökotrien reseptör antagonistleri verilebilir." ve "Orta persistan astımlı çocuklarda inhaler kortikosteroide lökotrien modifiye edici ilaç eklenmesi, inhaler kortikosteroidin orta doza artırilması kadar etkilidir." cümleleri çocuk hekimlerinin

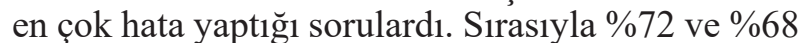
oranlarında yanlış cevap verildi. En fazla tam doğru cevap "Hastada astım kontrolü sağlanamadıysa; inhaler kortikosteroid dozunun 2 katına artırılması 
Tablo 1: Astimda Kullanilan İlaçlarin Klïnik ve Yan Etkï Bỉlgi Düzeyï Anket Formu.

\section{ASTIMDA KULLANILAN İLAÇLARIN KLINIIK VE YAN ETKİ BíLGİ DÜZEYİ ANKET FORMU}

1. Çocuklardaastım tedavisindeki günlük düşük doz inhalekortikosteroidlerin dozları nassıl olmalıdır, doğru doz aralığını işaretleyiniz.

İlaç Düşük doz (mcg/gün)

\begin{tabular}{lcccc} 
Budesonid inhaler & $50-100$ & $100-200$ & $200-500$ & $>500$ \\
\hline Budesonidnebul & $50-100$ & $100-200$ & $200-500$ & $>500$ \\
\hline Flutikazonpropiyonat & $50-100$ & $100-200$ & $200-500$ & $>500$ \\
\hline Siklesonid & $50-100$ & $100-200$ & $200-500$ & $>500$
\end{tabular}

2.Çocuklardaastım tedavisindeki günlük yüksek doz inhalekortikosteroidlerin dozları nasıl olmalıdır, doğru doz aralığını işaretleyiniz.

İlaç Yüksek doz (mcg/gün)

\begin{tabular}{lcccc} 
Budesonid inhale & $50-100$ & $100-200$ & $200-500$ & $>500$ \\
\hline Budesonidnebul & $50-100$ & $100-200$ & $200-500$ & $>500$ \\
\hline Flutikazonpropiyonat & $50-100$ & $100-200$ & $200-500$ & $>500$ \\
\hline Siklesonid & $50-100$ & $100-200$ & $200-500$ & $>500$
\end{tabular}

3.Çocuklardakortikosteroidlerinkullanımı ile ilgili bilgileri doğru yada yanlış olarak işaretleyiniz.

a- Kontrol altında olmayan ya da şiddetli astım büyümeyi ve erişkin boyu olumsuz etkilememektedir. D / Y

b- Günlükolarak 100-200 mcg inhale kortikosteroidle, büyümeüzerineolumsuzetkibildirilmemiştir. D / Y

c- Büyümegeriliği bütün inhalekortikosteroidlerde yüksek dozda kullanıldığında görülmektedir. D / Y

d- Büyümegeriliği dozdan bağımsız olup, çeşitli inhaleler arasında farklılıklar bulunmamaktadır. D / Y

e- İnhalekortikosteroidleri kullanan 2-10 yaş grubu çocuklar, adolesanlara göre büyüme geriliğine daha yatkındırlar. D / Y

f-İnhalekortikosteroidler, en etkili kontrol sağlayıcı ilaçlardır, bu nedenle her yaştaki astımlıda ilk tercih edilmesi önerilen tedavidir. D / Y

g-İnhalekortikosteroidler ile tedavi edilen astımlı çocukların erişkin boyu azalmakta ve normalden daha erken erişkin boyuna ulaşılmaktadır. D / Y

h- Çocuklardainhalekortikosteroidtedavisi, astım atak sıklığını ve acil başvurularını azaltıp, yaşam kalitesini düzeltirken, solunum fonksiyon testlerine, bronş aşırı duyarlılığına etki etmemektedir. D / Y

4-Astımlı çocuklarda yaşa göre önerilen inhalasyonyönteminlerinden ilk tercih edilmesi gerekeni işaretleyiniz.

Yaş

\begin{tabular}{|c|c|c|}
\hline 4 yaştanküçük & a) ÖDİ(Yüzmaskeliaracıtüpile) & b) kurutoz inhaler \\
\hline & c) Yüzmaskelinebülizer & d) ÖDİ (Ağız parçalı aracı tüp ile) \\
\hline 4-6 yaş & a) ÖDİ(Yüzmaskeliaracitüpile) & b) kurutoz inhaler \\
\hline & c) Yüzmaskelinebülizer & d) ÖDİ (Ağız parçalı aracı tüp ile) \\
\hline 6 yaştanbüyük & a) ÖDİ(Yüzmaskeliaracttüpile) & b) kurutoz inhaler \\
\hline
\end{tabular}

5) Ölçülüdozinhalerin (ÖDİ) aracı tüp ile kullanımı daha kolay, ilacın akciğere ulaşımı daha fazla, yan etkileri ve maliyeti daha düşük olduğu için nebülizasyon tedavisine; tüm yaşlarda tercih edilmelidir. D / Y

6) İnhalekortikosteroidlerin çocuklar üzerindeki potansiyel yan etkisi, osteoporoz ve kırıklardır. D / Y

7)İnhalekortikosteroid kullanımı çocuklarda katarakt gelişimine neden olmaktadır. D / Y

8)Aralıklı şikayetleri olan hastalarda semptomatik dönemlerde uzun etkili inhale $\beta 2$-agonist tedavisi önerilir.D/Y

9)İnhaleantikolinerjiklerin (ipratropium bromür) 5 yas ve altındaki çocuklarda günlük tedavide önemli bir etkisinin olduğu gösterilememiștir.Bu nedenle alevlenmeler haricinde tedavide kullanımı önerilmemektedir.D/Y

10)Süreklitedavigereksinimiolanhastalarda ilk seçenekortadoz inhale kortikosteroidlerdir, alternatifolaraklökotrienreseptörantagonistleriverilebilir. D / Y

11)Hastadaastım kontrol sağlanamadıysa; inhalekortikosteroid dozunun 2 katına arttırılması veya inhalekortikosteroidelökotrien reseptör antagonisti eklenmesi planlanabilir. D/Y

12)Acilservisteataktedavisindeçocuklarda b2 -agonistlerleipratropyumbromürünbirliktekullanımı, ilaçların etkinliğini arttırırken hastane yatışlarını azaltır. D / Y 13)Astımlı çocuklar acilde yoğun tedaviye rağmen hastaneye yatırılmak zorunda kalınırsa, nebulize b2-agonist ve sistemik kortikosteroidlere ek olarak ipratropiumbromid eklenmesinin bir faydası görülmemektedir. D/Y

14)Salmeterol, formoteroluzunetkili beta 2 agonistlerin inhale kortikosteroidlerilekullanımlarının, inhalekortikosteroidlerin dozlarının iki katına çıkarılmasından daha etkili olduğu gösterilmiştir. D / Y

15)Astımlı çocuklardaki ataklarda günde $0.5-2 \mathrm{mg} / \mathrm{kg}$ dozda ıvkortikosteroidin $3 * 5$ gün kullanımı,oral yolla alımından daha etkilidir. D / Y

16)Lökotrienreseptörantagonistlerinbeşyaşüstündekiçocuklardaklinikyararlanımıdüşükdoz inhale kortikosteroidlerleeşdeğerdir. $\mathrm{D} / \mathrm{Y}$

17)Lökotrienreseptörantagonistleri, egzersizebağlıbronkokonstrüksiyona karşı koruma sağlamamaktadır.D/Y

18)Düşükdoz inhale kortikosteroidlerleastımıkontroledilemeyençocuklardalökotrienreseptörantagonistlerinintedaviyeeklenmesi, klinikdüzelmeyiveataklarınazalmasınısağlamaktadır.D / Y

19)Ortapersistanastımlı çocuklarda inhalekortikosteroide, lökotrienmodifiye edici ilaç eklenmesi, inhalekortikosteroidin orta doza arttırılması kadar etkilidir. D / Y 20)Ortaveşiddetliastımlıçocuklardalökotrienmodifiyeediciilaçlar, inhale kortikosteroidlerealternatifolarakkullanılabilir. D/Y

21)5 yaşüstüçocuklarda,tekdozuzunetkili b2-agonist inhalasyonu, egzersizleindüklenenbronkokonstriksiyonubirkaçsaatengellemektedir. D / Y

22)Anti-IgE'nin (Omalizumab) tedavisi, uyguntedaviyerağmen, yılda 5 ya da daha fazla kez veya 20 gün ya da daha fazla süre hastanede yatan 12 yaș üstü çocuklarda önerilmektedir. D / Y

23) Aşağıdaverilenilaçlarınetkibaşlangıçzamanınıişaretleyiniz.

\begin{tabular}{|lclll|}
\hline Salbutamol & a) $0-30 \mathrm{dk}$ & b) $60-90 \mathrm{dk}$ & c) 3-4 saat & d) $\geq 12$ saat \\
\hline Oral prednizolon & a)0-30 dk & b) $60-90 \mathrm{dk}$ & c) 3-4 saat & d) $\geq 12$ saat \\
\hline İpratropium bromür & a) $0-30 \mathrm{dk}$ & b) $60-90 \mathrm{dk}$ & c) 3-4 saat & d) $\geq 12$ saat \\
\hline
\end{tabular}


veya inhaler kortikosteroide lökotrien reseptör antagonisti eklenmesi planlanabilir." sorusu ve "Anti-IgE'nin (Omalizumab) tedavisi, uygun tedaviye rağmen, yılda 5 yada daha fazla kez veya 20 gün yada daha fazla süre hastanede yatan 12 yaş üstü çocuklarda önerilmektedir." cümlelerine verildi. Doğruluk oranları sirasiyla $\% 87$ ve $\% 81,5$ 'idi. Astıml çocuklarda yaş gruplarına göre önerilen inhalasyon yöntemlerinden ilk tercih edilmesi gereken kullanım teknikleri çoktan seçmeli olarak çocuk hekimlerine yöneltilirken, yüzde 56 oranında doğru cevap verildi.

Testin tamamı değerlendirildiğinde toplam 40 parametre ve 100 puanlik testte hekimlerin ortalama 57,6 $\pm 10,4(30,7-84)$ puan aldikları hesapland1. Cinsiyet açısından değerlendirildiğinde kız cinsiyeti ortalama puan $157,6 \pm 10,1$ iken erkek cinsiyeti ortamla puan1 $57,8 \pm 11,3$ idi. Bu fark istatistiksel olarak anlamlı değildi $(p=0,881)$. Uzman hekimlerin ortalama puanı $65,2 \pm 10,6$ iken asistan hekimlerin ortalamas1 55,9 $\pm 9,6$ bulundu. Uzmanların bilgi düzeyleri daha yüksekti $(\mathrm{p}=0,001)$. Hekimlik süresi 5 yıldan fazla olanların ortalamas $61,8 \pm 11,9,5$

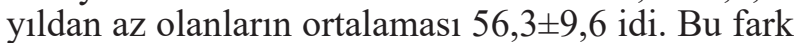
istatistiksel olarak anlamlıyd $(\mathrm{p}=0,001)$.

\section{TARTIŞMA}

Astım son y1llarda ülkemizde ve dünyada yükselme eğilimi göstermekte, mortalite ve morbiditesinde artış saptanmakta, sadece hastalara değil toplum üstünde de sosyal ve ekonomik bir yük oluşturmaya devam etmektedir. $\mathrm{Bu}$ sebeplerden astım tanı ve tedavisinin en erken ve doğru bir şekilde yapılması zorunlu hale gelmektedir. Ülkemizde özellikle Türk Toraks Derneği'nin yayınladığı The Global Initiative for Asthma kılavuzlarına da uygunluk gösteren astım tanı ve tedavisine yönelik kılavuzlar $(1,3)$ bulunmakta olup, yaptığımız çalışma ile çocuk hekimlerinin güncel yaklaşımlara ne kadar uydukları saptanmak istenmiştir. Hekimlerin cinsiyetlerine, uzman ya da asistan hekim olmalarına ve görev sürelerine göre araştırılmış ve karşılaştırılmıștır.

Astım tedavisi ve astım tedavisinde kullanılan ilaçların klinik ve yan etkileri konusunda, birçok uluslararası uzlaşı raporları ve rehberleri olmasına karşın, yapılan çalışmalar göstermektedir ki; hem toplumlar arası kültürel ve sosyoekonomik farkl1liklar hem de doktorların mezuniyet sonrası pratik ve teorik eğitimi, astımlı çocukların takip ve tedavileri ile ilgili bilgi birikimlerini ve klinik uygulamalarını etkilemektedir $(1,3,9)$.

Çalışmamızda, hekimlerin astım tedavisinde kullanılan ilaçlar ve astım tedavisine yaklaşım konularındaki bilgi düzeylerini değerlendirmeye yönelik sorulara verilen yanıtlara bakıldığında; cinsiyet, çalıştığ 1 kurum anlamlı olarak farklılık yaratmazken, uzman doktor olmanın ve hekimlik süresi 5 yıldan fazla olanların anlamlı olarak fark yarattığ1 görülmüştür. Uzman hekim olmanın bilgi düzeyi açısından farklı olması beklenen bir sonuçtur. Çalışma süresi açısından değerlendirdiğimizde; bulgularımız Yılmaz ve arkadaşlarının (9) çalışmasina uygunluk göstermektedir. Y1lmaz ve arkadaşlar1 değerlendirmelerinde asistanlık yapılan hastane, uzman çocuk doktoru olarak çalışma süresi ve muayenehane hekimliği parametrelerine göre tespitler yapmışlar ve bu parametrelere göre hekimlerin bilgi düzeyleri karşılaştırıldığında, aldıkları yanıtlar arasinda asistanlık yapılan hastane fark yaratmazken, muayenehane varlığ 1 ve çalışma süresinin fark oluşturduğunu gözlemlemişlerdir, cinsiyet açısından karşılaştırılma yapılmamıştır. Bunun aksine, yine ülkemizde Şekerel ve arkadaşlarının (10) çalışmasında ise uzmanlık süresinin bilgi düzeyi üzerine etkisinin olmadığ bulunmuştur. Sonuçlardaki bu farklılık çalışmanın düzeni, anketteki soruların farklılığ1, katılımcı sayısı gibi değişkenlere bağlı olabilir.

Calıșmamızda çocuk hekimlerinin astım tedavisinde kullanılan ilaçlar ve astım tedavisine yaklaşım konularındaki bilgi düzeyleri cinsiyet açısından anlamlı olarak farklılık yaratmadi. Ülkemizde Şekerel ve arkadaşlarının (10) 2006 yılında yaptıkları genel astıma yaklaşım çalışmasında da cinsiyet açısından farklılık saptanmamıştır. Fakat erkek hekimlerin akut astım atağında, kadın hekimlerin ise kronik astım atağında inhaler steroid tedavisini daha sık kullandıklarını gözlemlemişlerdir.

Çalışmamıza katılan hekimlerin yüzde 70' $\mathrm{i}$ inhaler kortikosteroidlerin en etkili kontrol sağlayıcı ve her yaştaki astımlıda ilk tercih ilaçlar olduğu konusunda hemfikirdi. Avrupa Birliği Ülkelerinde Lagerlov ve ark.'nın (11) 2000 yılında beş ayrı ülkede yaptıkları çalışmada da hekimlerin kortikosteroid tercihi çalışmamızla benzer sonuçlar göstermektedir. Yine Yılmaz ve arkadaşlarının (9) yaptıkları çalışmada da çalışmaya alınan çocuk doktorlarının $\% 94,1$ 'i astım tedavisinde inhaler kortikosteroid kullanım gerekliliğini belirtmișlerdir. Çalıșmamıza katılan hekimlerin \%64'ü astım ataklarında kortikosteroidin intravenöz ve oral formunun birbirine anlamlı üstünlüğünün olmadığını doğru olarak belirtmişlerdir. Benzer bir sonuç Avusturalya'da yapılan çalışmada gösterilmiş, hekimlerin yarısından fazlasının ağızdan steroid kullandığı saptanmıştır (12). Bunun aksine Yılmaz ve arkadaşlarının (9) yaptıkları çalışmada ise uzman çocuk doktorlarının steroid tedavisinde parenteral yolu daha çok benimsedikleri vurgulanmış. Bunun nedeni ise Türkiye'nin kültürel alt yapısına ve muayenehaneye başvuran hastaların sorunlarına daha hızlı çözüm istemelerine bağlanmıştır.

İnhaler steroidlerden olan siklesonid dozu çalışmaya katılan hekimler tarafından en fazla hata yapılan sorulardand1. Bunun nedeni bu molekülün ülkemizde son yıllarda kullanılmaya başlanmış olması olabilir.

Son yıllarda uzlaşı raporlarılya birlikte astımda hasta eğitiminin önemi vurgulanmıştır. $\mathrm{Bu}$ konuda yapılan çalışmalar hastaların çoğunun inhalasyon aletlerini uygun teknikte kullanmadiklarını göstermiştir. $\mathrm{Bu}$ da hastalara eğitim verecek konumda olan kişilerin bu konudaki bilgi düzeylerini gündeme getirmiştir. Çalışmamızda, astımlı çocuklarda yaş gruplarına göre önerilen inhalasyon yöntemlerinden ilk tercih edilmesi gereken kullanım teknikleri çoktan seçmeli olarak çocuk hekimlerine yöneltildi ve yüzde 56 oranında doğru cevap verildi. Ülkemizde yapılan çeşitli çalışmalarda da uzman doktorlar, asistan doktorlar ve hemșireler tarafından 
inhalasyon aletlerinin uygulanmasinda sorunlar olduğu gösterilmiştir (13-15). Avrupa'da yapılan bir çalışmada doktorların ölçülü doz inhalerleri sıkça reçete etmelerine rağmen, hangi tekniğin hangi yaş aralığında kullanılması gerektiği konusunda genel olarak yetersiz kalındığını belirtmişlerdir (11).

Yaptığımız çalışmanın tamamı genel olarak değerlendirildiğinde toplam kırk parametre ve yüz puanlık testte hekimlerin ortalama $57,6 \pm 10,4$ puan alması, çocukluk astımı tedavisi hakkında hekimlerimizin bilgi düzeylerinin yeterli olmadığını göstermektedir. Uzman hekim olanlar ve 5 y1ldan uzun süredir doktorluk yapanlarda bilgi düzeyi anlamlı olarak fazlayd1. Ulusal ve uluslararası astım rehberleri olması ve bunlara internet ortamında kolayca ulaşılabilir olmasına rağmen astım yönetimi konusunda bilgi düzeyimiz düşüktür. Ayrıca yaptığımız araştırma üniversite ve eğitim araştırma hastanelerini kapsamaktadır. Buna bakarak astım tedavi ve takibinde önerilmeyen veya yanlıș bilinen tedavilerin Türkiye'de gerçek kullanım oranın bizim araştırmamızdan daha fazla olabileceği sonucuna ulaşılabilir. $\mathrm{Bu}$ yüzden asistanlık eğitiminin yanında uzmanlık sonrası eğitimlere ağırlık verilmeli, pediatri kongrelerinde astım hakkındaki sunumlara ağırlık verilmelidir.

\section{KAYNAKLAR}

1. Global Strategy for Asthma Management and Prevention 2011 (update). www.ginasthma.org.

2. Ones U, Akcay A, Tamay Z, Guler N, Zincir M. Rising trend of asthma prevalence among Turkish school children (ISAAC phases I and III). Allergy 2006;61:1448-53.

3. Türk Toraks Derneği Astım Tanı Ve Tedavi Rehberi, 2014, Çocuk Astım Tanı ve Tedavi.

4. Bisgaard H. Delivery of inhaled medication to children. J Asthma. 1997;34(6):443-67.

5. Dolovich MB, Ahrens HC, Hess DR, et al. Device selection and outcomes of aerosol therapy: Evidence-based guidelines: American College of Chest Physicians/ American College of Asthma, Allergy, and Immunology. Chest 2005;127:335-71.

6. Turktaş İ, Selcuk ZT, Kalyoncu AF. Prevalence of asthma-associated symptoms in Turkish children. Turk J Pediatr. 2000;43:1-11.

7. Sastre J, Fabbri LM, Price D, Wahn HU, Bousquet J, Fish JE, Murphy K, Sears MR. Insights, attitudes, and perceptions about asthma and its treatment: a multi national survey of patients from Europe and Canada. World Allergy Organ J. 2016;9:13.

8. Karadag B, Karakoc F, Ersu R, Dagli E. Is childhood asthma still underdiagnosed and undertreated in Istanbul? Pediatr Int. 2007;49(4):508-12.

9. Yılmaz Ö, Söğüt A, Alkan S, Yüksel H. Genel çocuk uzmanlarının çocukluk çağı astımı ve tedavisi konusundaki bilgi durumu ve uygulamaları. Türk Ped Arş 2009; 44: 29-34.

10. Sekerel BE, Civelek E. Physicians' perception of childhood asthma in Turkey: more appropriate practice among female physicians. Pediatric Allergy and İmmunology. 2004; 372-375.

11. P Lagerlov, CC Veninga, M Muskova, E Hummers-Pradier, C Stalsby Lundborg, M Andrew, FM Haaijer-Ruskamp. Asth- ma management in five European countries: doctors' knowledge, attitudes and prescribing behaviour. Drug Education Project (DEP) group. European Respiratory Journal 2000 15: 25-29.

12. Coates JR, Steven ID, Beilby J, Coffey G, Litt JC, Wagner C. Knowledge of and reported asthma management among South Australian general practitioners. Br J Gen Pract 1994; 44: 123-6.

13. Görgüner M, Mirici A, Kaynar H, Özbakıș G, ve ark. Hekimlerimizin inhalasyon cihazlarının kullanımıyla ilgili bilgilerinin değerlendirilmesi. Solunum 1996;20:243-50.

14. Akkaya E., Yılmaz A., Baran A., Baran R., Sarıbaş E., Kılıç Z., Şadoğlu T.: İnhalasyon cihazlarının kullanım tekniklerinin sağlik personeli ve hastalarda değerlendirilmesi, Solunum, 20, 235-242; 1996.

15. Dinmezel S., Özdemir T., Öğüş C., Çilli A.: Hemşire eğitiminin hastaların inhalasyon cihazlarını kullanmaları üzerine etkileri, Akciğer arşivi, 4(2), 89-94, ;2003. 